\title{
Risk-based access control at Mount Isa Copper Operations
}

\author{
GS Potgieter Mount Isa Mines Limited, A Glencore Company, Australia
}

AB Grubb Mount Isa Mines Limited, A Glencore Company, Australia

\begin{abstract}
Mount Isa Copper Operations (MICO) is one of the oldest and deepest mines in Australia, comprising the largest underground network of mine development in the world. During the early operational years, ground support, particularly surface support, was not routinely installed. Although rehabilitation in recent years has drastically reduced the amount of tunnel without support, there remain tens of kilometres of excavation with limited to no ground support installed. In addition, older development was often mined within close proximity to unfilled or partially filled stopes and vertical openings. The voids pre-date modern 3D mine plans and scanning technology. Furthermore, access to the voids to conduct scans is limited, this results in an imperfect understanding of the void sizes and proximity to accessible drives. The lack of ground support and knowledge of void status poses significant ground failure risks at MICO.
\end{abstract}

A significant increase in rock related near-hit incidents occurred during the second half of 2014 and the first half of 2015. A number of these incidents had the potential to cause severe or fatal harm. The incidents triggered internal investigations that aimed at understanding and reducing the ground failure risk. The outcome of the investigations was the creation of a series of interlinked systems, namely the tunnel condition risk assessment (TCRA), mine closure areas (MCA), ground awareness training (GAT), vertical opening pillar hazard assessment and control (VOPHAC), stope void review (SVR), manual scaling crews, fall of ground database and the quality assurance/quality control management plan (QA/QC MP). The individual components of the system are specialised and simple. However, the system is comprehensive and robust. Each of the components, as well as how they interlink, is discussed within this paper.

The interlinked systems and practices provide controls and have proven to be effective at reducing the ground failure risks. Although the systems were developed at MICO, they have the potential to be easily adapted and utilised at other mine sites.

Keywords: Mount Isa, rock mechanics, risk, hazard, ground failure, ground control, tunnel condition risk assessment, mine closure areas, quality assurance/quality control

\section{Introduction}

Mount Isa Copper Operations (MICO) is an underground sublevel open stope copper mine situated in North West Queensland. The mine is one of the oldest and deepest mines in Australia, comprising one of the largest underground networks of mine development in the world. From the 95 -year-old operation containing over $500 \mathrm{~km}$ of accessible development, $6.7 \mathrm{Mtpa}$ of copper ore is concentrated and smelted at onsite processing facilities before it is transported to the Townsville copper refinery for final treatment to saleable copper cathode. As an operation of this age and size, MICO is exposed to significant rock failure hazards.

Within our industry, the number one objective of the mine operator is to achieve production targets safely. Critical to our people's safety is the understanding and controlling of their exposure to the hazard of rock failure. The pursuit of this need has led to the creation of an entire engineering discipline with many subspecialties, schools, societies and journals. Undeniably, rock failure related hazards are complex. As rock mechanics engineers, we love this complexity; a love not always shared by our colleagues.

Growing from this complexity are countless tools, rules of thumb, methods and increasingly more detailed elasto-plastic computer models, designed to help us understand and deal with the complexity. However, with 
so much available and so much at stake, it is easy for site rock mechanics and responsible managers to get overwhelmed at the prospect of controlling something they cannot measure with certainty, that is subject to constant (usually immeasurable) change, and that can take lives.

This paper follows iterative advances in our approach to managing rock failure hazards at MICO. We present our overarching risk management framework, and describe the operational systems which underpin and interact to manage the risk of ground failure for our people. A common theme throughout the paper is the evolution of thought and focus that has occurred within our systems, and which has led us to want to share this with industry.

The paper does not present any advances in rock mechanics theory, nor does it intend to be revolutionary in its approach to risk management. What we intend is to present our framework in a way that is accessible to professionals and operations to assist them to navigate through the complexity of rock failure hazards in an active operation.

Steve Jobs said, "Simple can be harder than complex: You have to work hard to get your thinking clean to make it simple. But it's worth it in the end because once you get there, you can move mountains." (Jobs 2015). We have worked hard to simplify our thinking surrounding this hazard and hope that sharing will assist others to improve safety within our industry.

\section{$2 \quad$ History of risk management}

Over the course of many years, geotechnical risk management at MICO has undergone significant change.

The overarching ground control management plan (GCMP) has traditionally been a very comprehensive document that covered not only very specific rules and design guidelines, but also laid out responsibilities and detailed specific risk mitigating strategies. The GCMP was reviewed internally every year and externally every third year. To support the GCMP, we created procedures that were intended to address specific risks. Our procedures were almost independent of the GCMP and would be individually updated to address real or perceived failings. This is how most mines' documentation and systems are structured. We had every reason to believe that we had a solid risk management plan. However, we continued to have an unacceptably high number of rockfalls, many of which had the potential to result in serious injury (Figure 1). This risk was unacceptable.

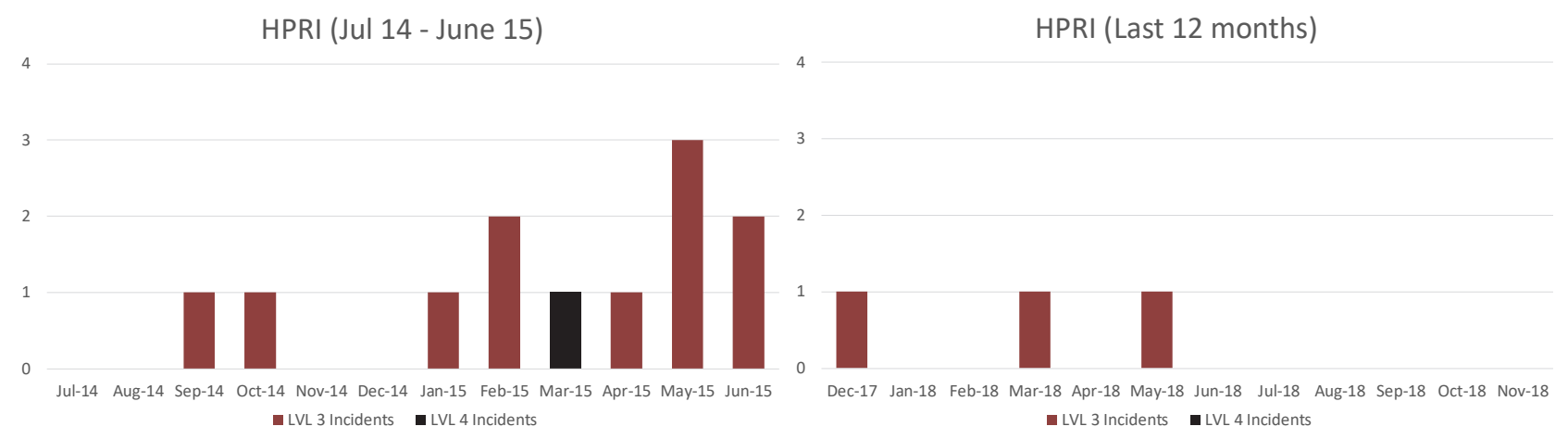

Figure 1 High potential risk incidents (rockfalls) July 2014 to June 2015, compared to last 12 months

Introduction of the Glencore corporate safety framework, 'SafeWork', and critical control concepts (International Council on Mining and Metals (ICMM) 2015) to the site helped us to look critically at our management of rock failure hazard. We were prompted to challenge our thinking and traditional approach, identifying oversights such as critical controls that were described in a dot point, mid-document, mid-page of the GCMP. The GCMP did not explain in simple terms how we managed risk. 
We manage risk by making sure that the areas people work in are well-supported, and the areas that are not well-supported are quarantined.

The journey has not been easy. However, as we have progressed and our understanding has evolved, we have been able to make iterative changes that have made a measureable difference.

\section{Framework of risk management}

It is through the ICMM methodology (ICMM 2015) that we moved towards the framework we present in this paper. As we stripped away the complexity by focusing on what was critical, we started to understand it is not a single idea or process but a complex interconnected series of systems and checks that manages the risk. Each management system component is as simple and robust as possible to remain sustainably achievable. Reflecting Aristotle's quote "The whole is greater than the sum of its parts", by focusing carefully on how the components interact and work with each other, the comprehensive benefit of the combined system exceeds that of each component in isolation.

At MICO, two of the most critical systems are the tunnel condition risk assessment (TCRA) and mine closure areas (MCA). Together, they are the core of risk-based access control. An effective quality assurance/quality control $(Q A / Q C)$ program that verifies these and the other supporting systems are working.

The choice to not speak about the hierarchy of controls is deliberate. Although the hierarchy of controls is an invaluable tool when discussing control effectiveness, it loses its value when being applied to an interconnected system of controls where everything comes down to people doing the right things, using systems and equipment as intended.

\section{$4 \quad$ Key concepts}

The bowtie framework was used to articulate consequences and threats, and provide clarity about our site understanding of the complex hazard. This understanding underpins the creation of our system and will be vital to the adaptation by the reader to their application.

The authors acknowledge that the simplification of a complex problem is not without risk, especially when that problem is part of a wider interlinking system. We do not intend that this framework is the 'right' answer, or breaks the complex problem into isolated simple parts. However, by standing back and viewing the hazard from a position without emotion or technical bias, we believe the operator can work through the complexity to tailor controls to their operation.

Fundamentally, not every rockfall has the potential to kill or maim. However, every time there is a control failure, there is a potential for a fatal incident to occur. The focus is on ensuring the controls do not fail through assurance and verification of the controls.

\subsection{Consequences}

When assessing the potential outcomes associated with complex problems, it is easy to become overwhelmed and enter the rabbit hole of possibilities, events and outcomes. It is also possible to become restricted to well-known or tangible consequences, missing low-likelihood catastrophic events. To simplify the endless potential combinations of events surrounding rock failure hazard, we simplified these to three material consequences represented on the right side of our bowtie (Figure 2). 


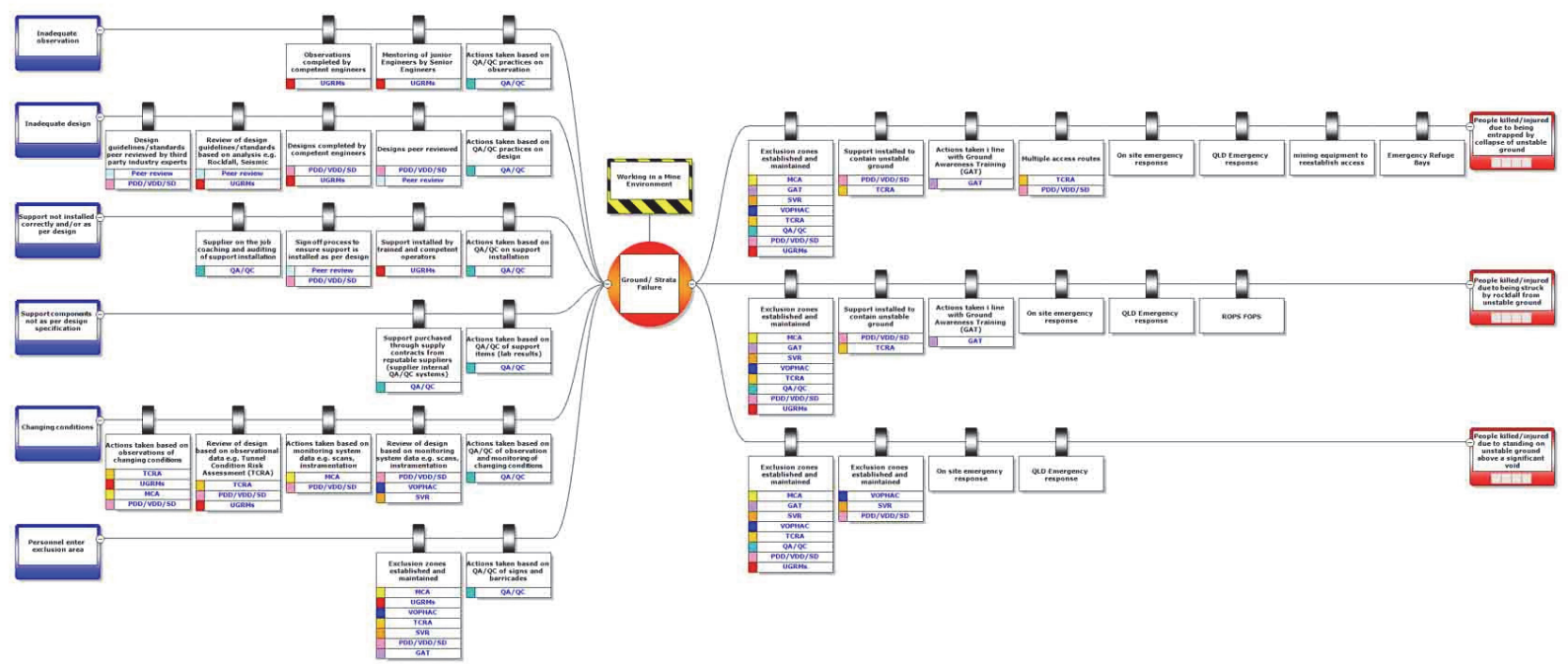

Figure 2 Unstable ground bowtie

\subsubsection{Type one: Person being struck by rockfall from unstable ground}

Type one involves a rock containing enough kinetic energy to cause significant damage, striking a person resulting in injury or death. The reason behind the rock moving, the size of the rock and the speed of the rock can, and does, vary significantly. For classification, these reasons do not matter.

\subsubsection{Type two: Person falling into void due to collapse of unstable ground}

Type two refers to rock mass that is supporting a person, failing, and allowing them to fall into a void resulting in injury or death. The reason behind the failure, the size of the failure and the dimensions of the void vary significantly. For classification, these variations, also, do not matter.

\subsubsection{Type three: Person entrapped by the collapse of unstable ground}

Type three is where a rockfall occurs that is of such significant mass that it results in the entrapment of a person resulting in injury or death. This consequence differs from type one and type two consequences, primarily regarding mitigating controls and response options such as multiple access routes and the ability to re-establish access through the use of mining equipment. Interestingly, a type three consequence is simply a large type one or type two event that does not immediately affect a person.

These hazard classifications do not differentiate between mining methods or mining depths applied to open pit, massive or narrow tabular underground mining geometries.

\subsection{Threats}

Consider rockfall prevention controls as a chain (Figure 3), in which the failure of a single link causes failure of the entire chain. Each link is dependent on the previous; if the bolts are too short, it does not matter if they are installed correctly; if the observations were flawed, the design is unlikely to be correct. Our controls protect our people from the bowtie threat, as explained in the following section. 


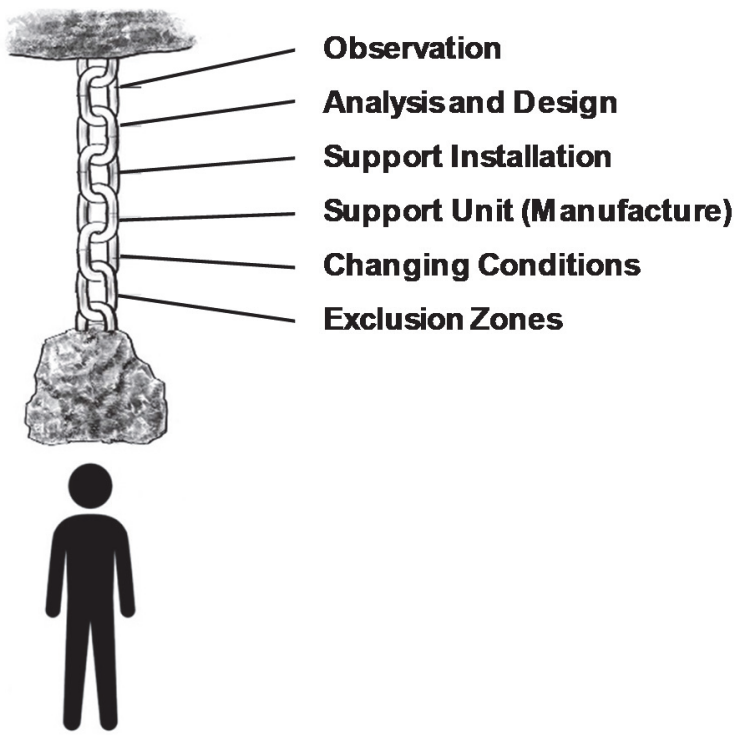

Figure 3 Threats and consequences

\subsubsection{Inadequate observation}

The first link in the chain is observation. Missing a critical detail during the inspection stage compromises all subsequent processes. Generally, observation skills do not receive the focus they deserve. Mentoring of young engineers, giving them time underground to learn, and constantly checking their work is the only way to ensure observational skills are developed.

\subsubsection{Inadequate analysis and design}

The second link in the chain is design and analysis. Substantial focus is directed towards this aspect and, as a discipline, we understand the limitations of the empirical and numerical tools we employ. Rock is not a uniform material. More than most engineering disciplines rock mechanics designs use simplification, assumptions and models. Peer review, experience and following methodologies are fundamental to success.

\subsubsection{Inadequate support unit (manufacture)}

The third link is the materials comprising the support systems; ranging from the rock that can be damaged through poor mining practices to the chemical composition of the fine sand used in shotcrete that can chemically attack shotcrete post-application. Although suppliers, who are often also manufacturers, generally focus on these aspects, in our experience it is advisable to visit the factories, ask for copies of internal QA/QC testing, send materials away for third-party tests and, where possible, conduct in-house testing of materials. The in-house tests can be simple sieve tests of shotcrete materials, using torque wrenches to test the shear pins of resin bolts, or as laboratory tests like round determinate panel (RDP) testing. Conducting the test and sharing the results with the suppliers often drives good behaviours. The adage 'what gets measured, gets managed' is as true here as anywhere.

\subsubsection{Inadequate support installation}

The fourth link refers to the support unit installation. Even if a combination of good design and high-quality support is used, it becomes nullified if poorly installed. Bolt resin can be damaged through the process of undermixing or overmixing, and shotcrete strength is weakened if poorly compacted. Although these are examples of poor installation, neither are likely to be detected before failure. Ongoing coaching and training of operational and technical staff generally provide better control and assurance than most testing programs. On-the-job coaching of operators, signing off of completed work, and workplace observations against a checklist are the best defence. 


\subsubsection{Changing conditions}

The fifth link in the chain is condition monitoring. Mining excavations are subjected to significant stress changes throughout the operating life of the project. Mine support is often required and recommended to provide support far beyond the intended lifespan of the original design. Pillars, whether oriented vertically or horizontally, undergo time-dependent deterioration. Unless monitoring of ground support and excavation conditions occur, deterioration of the support capacity is not detectable before failure.

\subsubsection{Personnel enter exclusion zones}

The final link is the creation of exclusion zones. Local exclusion zones are created where it is identified there is a specific known or suspected hazard. The MCA covers the majority of the mine and allows focused application of the controls to the areas accessed by people. The MCA is one of the interlinked systems discussed in Section 4.6. Essentially, if a rockfall occurs in an inaccessible area, there is no risk.

\section{$5 \quad$ MICO interlinked systems}

At various times in recent history, MICO has implemented controls focused on the threats and consequences discussed previously with varying success and application continuity. The rest of this paper focuses on the current controls; specifically, how the different components interact to form the interconnected system (Figure 4).

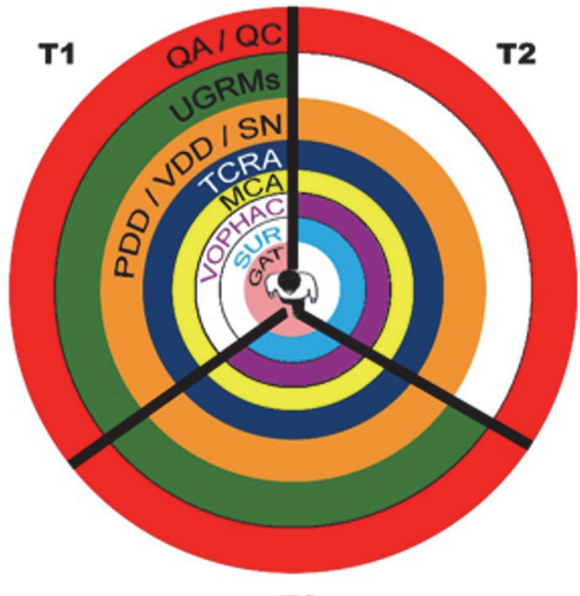

T3

\author{
Barriers \\ QA/QC - Quality con troland Quality Assu rance \\ UGRM S- Underground Rock Mechanics \\ PDD/VDD/SN - Prelim in ary Developm en t \\ Design / Vertical Developm ent Design / Stope \\ Design \\ TCRA - Tunnel Con dition Risk Assessm en t \\ MCA - Mine Closu re Areas \\ VOPHAC - Vertical Opening Pillar Hazzard \\ Assessm ent Control \\ SVR - Stope void Review \\ GAT - Ground Awaren ess Training \\ Consequence \\ $\Pi$ - Person being struck by rockfall \\ T2 - Person falling into void \\ T3 - Person entrapped by a collapse
}

Figure 4 Interlinked systems forming layers of control

Each of these systems are discussed in the following sections. However, MCA, TCRA and QA/QC are discussed in the greatest detail.

\subsection{Underground rock mechanics}

After a short period of operational crew time, all rock mechanics are initially placed in the role of underground rock mechanic for a period of between six and eight months dependant on their previous experience.

Tactically, the underground rock mechanic has the intent of reducing rockfalls and improving rock mechanics response times to operational issues. These goals are achieved through:

- On-request inspections to provide ground control recommendations.

- Conducting rockfall investigations.

- Completing the TCRA.

- Assistance underground personnel with access to MCA. 
Strategically, the role is used to develop observational skills for junior engineers by having them based underground walking large sections of the mine to complete TCRA, investigating all reported rockfalls and responding to stability concerns. The underground rock mechanics team consists of four engineers working $8 / 6$ back-to-back with a lead engineer facilitating a coaching and mentoring program.

\subsection{Quality assurance/quality control}

A significant evolution in recent times at MICO is our acknowledgement of the importance and power of an effective QA/QC system. The intent of the QA/QC program at MICO is to assure that every link of the chain is in place and effective. The program is achieved through a combination of desktop reviews and inspections by rock mechanics and other experienced personnel. The QA/QC program is deliberately focused on achieving a high level of assurance of the critical controls. See Figure 5 for an example of a QA/QC check.

Each system is audited on a monthly basis by a dedicated QA/QC engineer whom reports to the operational services superintendent. Based on the results of the audits, the testing frequency is then increased or decreased on a per item basis (Figure 6). This allows focus to be moved to areas of concern. To the best of the authors' knowledge, $\mathrm{QA} / \mathrm{QC}$ is not routinely undertaken to this level on mine sites.

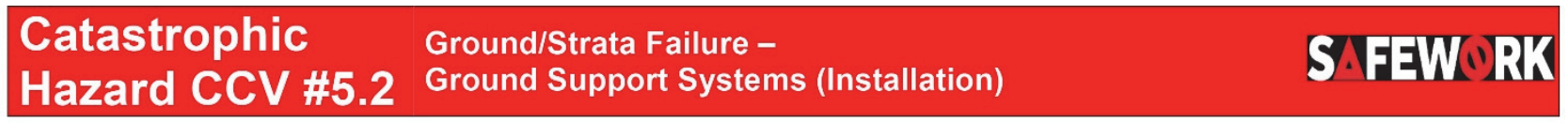

\begin{tabular}{|c|c|c|c|c|c|}
\hline \multirow{5}{*}{$\begin{array}{c}\text { GROUND/STRATA } \\
\text { FAlLRE }\end{array}$} & \multicolumn{2}{|c|}{ Fatal Hazard Protocol } & \multicolumn{3}{|l|}{ Ground / Strata Failure } \\
\hline & \multicolumn{2}{|c|}{ Critical Control } & \multicolumn{3}{|c|}{ Ground support systems (Installation) } \\
\hline & \multicolumn{2}{|l|}{ Verified by } & & & Date \\
\hline & \multicolumn{2}{|c|}{ Critical Control Owner } & & & Department \\
\hline & \multicolumn{2}{|c|}{ Task/s / Equipment } & & & Location \\
\hline \multicolumn{2}{|c|}{ Performance Requirement } & \multicolumn{2}{|c|}{ Verification Activity } & Result & Comments \\
\hline \multirow{10}{*}{\multicolumn{2}{|c|}{$\begin{array}{l}\text { 1. Installation - Ground support } \\
\text { components are installed as per } \\
\text { OEM and support design }\end{array}$}} & \multicolumn{4}{|c|}{ Review development inspection register to confirm: } \\
\hline & & \multicolumn{2}{|c|}{$\begin{array}{l}\text { 1.1 Did a rock mechanic inspect the ground support } \\
\text { installed in the development? }\end{array}$} & $\begin{array}{l}\text { Pass } \square \\
\text { Fail } \square\end{array}$ & RM inspection D-Base Check \\
\hline & & \multicolumn{2}{|c|}{$\begin{array}{l}\text { 1.2 Was the ground support installed to design } \\
\text { specifications? }\end{array}$} & $\begin{array}{l}\text { Pass } \square \\
\text { Fail } \square\end{array}$ & RM inspection PDD Check \\
\hline & & \multicolumn{4}{|c|}{ Review a selection of in-field ground support installation inspection records: } \\
\hline & & \multicolumn{2}{|c|}{$\begin{array}{l}\text { 1.3 Was ground support correctly installed to OEM } \\
\text { specifications? }\end{array}$} & $\begin{array}{l}\text { Pass } \square \\
\text { Fail } \square\end{array}$ & RM inspection D-Base Check \\
\hline & & \multicolumn{2}{|c|}{$\begin{array}{l}\text { 1.4 Was ground support correctly installed to ground } \\
\text { support design? }\end{array}$} & $\begin{array}{l}\text { Pass } \square \\
\text { Fail } \square\end{array}$ & RM inspection PDD Check \\
\hline & & \multicolumn{2}{|c|}{$\begin{array}{l}\text { 1.5 Were variances to design or specifications } \\
\text { identified and addressed appropriately? }\end{array}$} & $\begin{array}{l}\text { Pass } \square \\
\text { Fail } \square\end{array}$ & RM inspection D-Base Check \\
\hline & & \multicolumn{4}{|c|}{ Review a selection of manufacturer's representatives installation (rig) audits: } \\
\hline & & \multicolumn{2}{|c|}{$\begin{array}{l}\text { 1.6 Was ground support correctly installed to OEM } \\
\text { specifications? }\end{array}$} & $\begin{array}{l}\text { Pass } \square \\
\text { Fail } \square\end{array}$ & Rig audits \\
\hline & & \multicolumn{2}{|c|}{$\begin{array}{l}\text { 1.7 Were variances to specifications identified and } \\
\text { addressed appropriately? }\end{array}$} & $\begin{array}{l}\text { Pass } \square \\
\text { Fail } \square\end{array}$ & RM inspection D-Base Check \\
\hline
\end{tabular}

\begin{tabular}{|l|l|l|l|l|}
\hline Process Owner: & Verifiers: & Status: & Rev No: 1.0 & Issue Date: \\
\hline
\end{tabular}

Figure 5 Example of a quality assurance/quality control check 


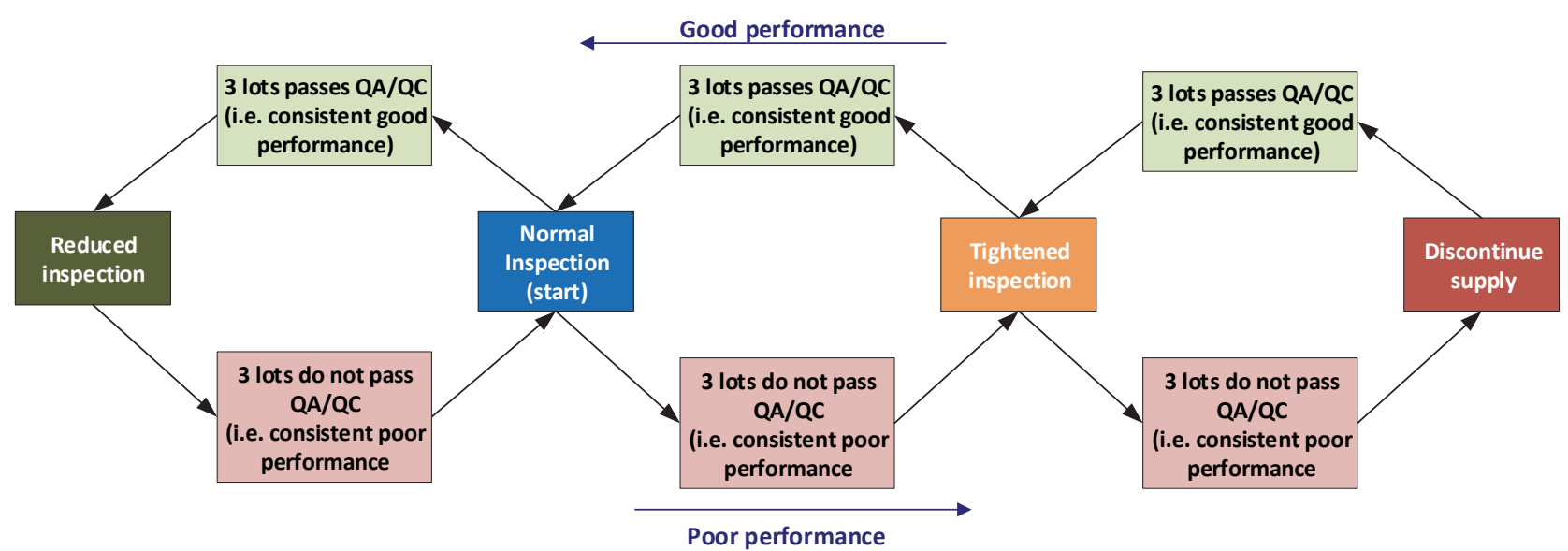

Figure 6 Quality assurance/quality control process

\subsection{Peer review}

Peer review is integral to an iterative design process, moving a design from long-term planning to execution.

Every design is reviewed. The review is performed by senior engineers who check and countersign each document before issuing. Engineers also undertake as-built and close-out inspections to ensure that work is completed as per the design.

Broadly, we define:

- Designers (typically engineers): Responsible for ensuring that guidelines are followed, that all relevant information is provided and all hazards are identified and controlled as low as reasonably practicable.

- Checkers (typically senior engineers): Ensure that information, hazards and controls provided by designers are true and correct to the best of their knowledge; appropriate logic has underpinned the control of hazards and supporting procedures, standard guidelines and forms have been utilised.

- Approvers (typically managers): Ensure the preliminary development design adequately details the hazards and controls ensuring the work is planned to an acceptable level of risk before approving the work for commencement.

\subsection{Preliminary development design/vertical development design/stope design}

Essentially, all mining at Mount Isa can be divided into four categories; horizontal development, vertical development, stoping and 'everything else'. The fourth category will have bespoke designs. The first three categories, that account for the vast majority of mining, each have their own suite of design documents. Moreover, of these documents, the design templates are arguably the most important. These are preliminary development design (PDD), vertical development design (VDD) and stope design (SD).

The intent of the specific design templates is that they act as a guide that serves to communicate past lessons learnt and act as a memory aid. The design templates have evolved over decades. They are regularly updated to include new lessons. It is these documents that are scrutinised during the peer review process. Each template has an extensive guide that details the intent of each section. The design guides are not intended to replace good engineering thinking, but rather to enhance it.

\subsection{Tunnel condition risk assessment}

The TCRA is the product of an iterative process dating back 17 years initially referred to as the mine-wide risk assessment (MWRA). The intent has always been to minimise the risk of people being impacted by rockfalls.

In 2001, the original MWRA was designed to provide a systematic, auditable framework for assessing (analysing and evaluating) the geotechnical risks to mine personnel associated with potential rockfalls in mine 
access ways, infrastructure, and other entry areas through a risk management process (Thin \& Westerman 2001). The MWRA was an adaptation of the Western Australian Ground Control Working Group's (WAGCWG) Geotechnical Risk Assessment Guideline (WAGCWG 2000), which in turn is based on the Australian standards for risk assessment AS/NZS 4360:1999 (Standards Australia 1999).

In 2005 the MWRA was extended by development of a method better able to predict the likelihood of rockfall using quantitative inputs (Monk 2005). The new MWRA included the creation of a rockfall database, and addressed problems with the initial MWRA, such as it being difficult to audit and having a lack of consideration of blast vibrations. While the new MWRA fulfilled these goals, it introduced a level of complexity that made it unsustainable for a mine as large as MICO.

In 2013, GS Potgieter revised the MWRA, simplifying it in an attempt to make annual completion achievable. The new MWRA placed focus on identifying and controlling risk rather than rockfall prediction. It also reintroduced the earlier work regarding exposure. While this was somewhat successful, it was still unsustainable and only focused on the main travelling ways and declines.

In 2015, GS Potgieter updated the MWRA to the TCRA introducing a clear scoring criteria based on pictures and a score matrix (Figure 7). This was done to reduce variability between engineers, minimise administration overheads, and integrate broader checks (e.g. "false ceilings" preventing observation of the backs). At the same time, he updated the prediction tools based on the rockfall that occurred between 2005 and 2015, and most importantly, incorporated the mine closure areas allowing the TCRA to address all accessible drives.

A matrix was selected because:

- It was simple - a significant consideration when conducting an assessment on this scale.

- It allows two pieces of information to be encoded into a single number.

- It standardises the assessment and increases repeatability between engineers.

- Degraded support or poor conditions alone are not enough to reliably predict rockfalls. It is the confluence of these two factors that determine the hazard.

\begin{tabular}{|c|c|c|c|c|c|c|}
\hline & & $\begin{array}{c}\text { Limited to no deformation of rock } \\
\text { mass indicated by scatting, } \\
\text { occasional scats in mesh }<4 \text { scat } \\
\text { per bolt } \\
\text { or }\end{array}$ & $\begin{array}{c}\text { Minor deformation of rock mass } \\
\text { indicated by scatting, Frequent } \\
\text { scats under mesh clustering of } \\
\text { scats but no visible bagging } \\
\text { or }\end{array}$ & $\begin{array}{l}\text { Moderate deformation of rock } \\
\text { mass with bagging of mesh } \\
\text { partially obscures underlying rock } \\
\text { mass. Signs minor bucking. } \\
\text { or }\end{array}$ & \begin{tabular}{|c|} 
Sup port elements pulling into \\
rock mass. Significant bagging \\
obscures over large sections of \\
rockmass. Significant bucking \\
and dilation. \\
or \\
\end{tabular} & Rockmass Damage \\
\hline & & $\begin{array}{l}\text { No cracking of shotcrete } \\
\text { or }\end{array}$ & $\begin{array}{c}\text { Cracks visible in shotcrete } \\
<1 \mathrm{~mm} \\
\text { or }\end{array}$ & $\begin{array}{c}\text { Cracks visible in shotcrete } \\
1-40 \mathrm{~mm} \\
\text { or }\end{array}$ & $\begin{array}{l}\text { Cracks visible in shotcrete } \\
>40 \mathrm{~mm} \\
\text { or }\end{array}$ & Shotcrete condition \\
\hline & & $\begin{array}{c}\text { Drive excavated to original } \\
\text { design, } 1 / 2 \text { barrels may be } \\
\text { visible. }\end{array}$ & \begin{tabular}{|c|}
$\begin{array}{c}\text { Original design visible however } \\
\text { blocks visibly missing from } \\
\text { perimeter }\end{array}$ \\
\end{tabular} & $\begin{array}{c}\begin{array}{c}\text { Original design discernible } \\
\text { however significant sections of } \\
\text { perimeter are removed }\end{array} \\
\end{array}$ & $\begin{array}{l}\text { Original de sign no longer } \\
\text { discernible }\end{array}$ & Drive Profile \\
\hline $\begin{array}{l}\text { Shotcrete dry no signs of } \\
\text { discolouration }\end{array}$ & $\begin{array}{l}\text { Surface corrosion of } \\
\text { elements but no surface } \\
\text { penetration }\end{array}$ & & & & & \\
\hline $\begin{array}{l}\text { Signs of discolouration on } \\
\text { shotcrete indication of } \\
\text { historic water flow }\end{array}$ & $\begin{array}{c}\text { Some surface penetration } \\
\text { indicated by slight swelling } \\
\text { of and minor flaking on } \\
\text { elements }\end{array}$ & & & & & \\
\hline $\begin{array}{l}\text { Shotcrete dry but adjacent } \\
\text { rockmass is damp }\end{array}$ & $\begin{array}{c}\text { Significant surface } \\
\text { penetration indicated by } \\
\text { significant changes in } \\
\text { element shape and } \\
\text { thickness }\end{array}$ & & & & & \\
\hline Shotcrete visibly damp & $\begin{array}{c}\text { Visible failure of support } \\
\text { elements, plates on the } \\
\text { floor, sections of mesh } \\
\text { missing or hanging loose. } \\
\text { or } \\
\text { No support installed. }\end{array}$ & & & & 1 & \\
\hline
\end{tabular}

Figure 7 Tunnel condition risk assessment matrix

During the TCRA rating process, the rock mechanics engineer considers the exposure based on the frequency of which the drive is accessed, and the type of access (pedestrian or vehicle). The level of exposure in a crib room is significantly higher than in a truck loop, even though both areas have people travelling on foot. This assessment is qualitative and is based on the engineer's training, experience and knowledge of the mine. 
Likelihood is used as a proxy for risk and is determined through the consideration of both exposure and probability. Based on the risk rating, the rock mechanics engineer determines the actions required to control and limit the risk. Where uncertainty exists around the level of risk, senior staff are consulted. The rock mechanics engineers are given the following guidance as to what level of risk is acceptable:

- Low (green): requires no action plan, continue with current controls (e.g. TCRA next year).

- Medium (blue): requires verification of current control effectiveness and future planning of risk reduction as appropriate (e.g. check scale, borescope inspection of split sets, barricading during firing, future rehabilitation, etc).

- High (yellow): action to be planned and scheduled, consideration to be given to alternative routes to reduce exposure until the action plan is completed (e.g. rehabilitation of drive).

- Extreme (red): immediate action to be planned and scheduled, areas to be barricaded off until the risk is modified (exposure reduced until the probability of rockfall is reduced).

In addition to assessing ground conditions during the TCRA process, all current and historical vertical openings and stopes are reviewed. These voids are investigated before the inspection is completed to limit potential type two consequences from occurring. Signs and barricades are checked to ensure that what is physically installed underground matches both the mine plans and the signs and barricades database. The area above false ceilings is inspected to assess the risk of hidden rockfall hazards.

The volume of work required to conduct these checks is considerable. Without dedicated underground rock mechanics roles, this work cannot be completed.

\subsection{Mine closure areas}

The MCA system underpins the success of the risk management system so is described in detail. Created in the middle of 2015 following a period of unacceptable rockfall incidents (Figure 1), the MCA both removes people from potentially hazardous areas and allows other control systems to be completed effectively and sustainably. As a general approach, unless it is needed for regular access, a drive is moved into MCA regardless of its condition. Without the introduction of the MCA, many other components of our system would be too large to complete; the previous MWRA and vertical opening management plans (VOMP) are examples.

By definition, every part of the mine that is not in an MCA is inspected by the TCRA. The TCRA is critical for long-term safe access. However, the volume of work required to conduct these checks is considerable. Reducing the areas requiring access is the simplest way to limit areas requiring regular monitoring. On the mine plans, all MCA areas are shaded yellow (Figure 8).

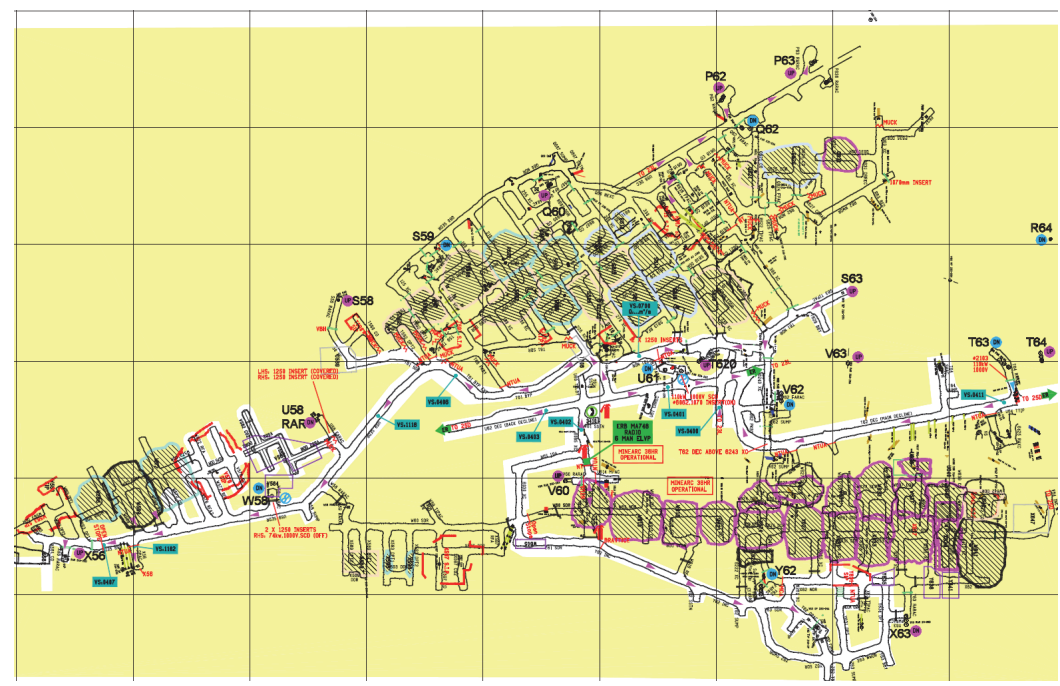

Figure 8 Plan of area 24A showing MCA a yellow areas. 


\subsubsection{The creation of mine closure areas}

The creation of MCAs was a collaborative exercise comprising nine phases (Table 1).

Table 1 Creation of the mine closure areas

\begin{tabular}{ll}
\hline Phase & Process \\
\hline 1 & $\begin{array}{l}\text { Map the process, draft the procedure, conduct risk assessment and complete appropriate } \\
\text { change management. }\end{array}$ \\
2 & $\begin{array}{l}\text { Print level maps and invite stakeholders (ventilation, electrical, mine pumping, etc.) to raise } \\
\text { areas of concern and highlight pieces of infrastructure that require any form of access. }\end{array}$ \\
3 & $\begin{array}{l}\text { Gather feedback from experienced employees (both technical staff and operations) } \\
\text { regarding known hazardous areas that key stakeholders may have missed. }\end{array}$ \\
4 & $\begin{array}{l}\text { Review highlighted maps with all stakeholders to confirm critical infrastructure will not be } \\
\text { barricaded. }\end{array}$ \\
6 & $\begin{array}{l}\text { Rollout MCAs and expected changes to the workforce. } \\
\text { plans. }\end{array}$ \\
7 & $\begin{array}{l}\text { Manage all areas that were not discovered during phases two to five. Move signs and } \\
9\end{array}$ \\
\hline
\end{tabular}

The creation of the MCAs has proven to be the least taxing part of the process. Maintaining barricades between MCAs and open drives, as well as reopening MCAs, have been significantly more difficult to maintain and monitor.

\subsubsection{Access to the MCA}

Once development has been placed into an MCA, and confidence has been gained in barricade location and maintenance, the next logical step is to determine how to gain access into these areas, if required, safely. Access requires that all hazards controlled by barricades be assessed and subsequently the assessment of all non-rock related hazards, such as irrespirable and noxious atmosphere.

To gain access to an MCA, the applicant must formally review the signs and barricades log to familiarise themselves with known hazards, review the vertical opening pillar hazard assessment and control (VOPHAC) and stope void reviews (SVR) to understand the status of present voids, consult the ventilation department and determine the requirement for a rock mechanic escort. The rock mechanics superintendent must grant access to an MCA area.

\subsubsection{New development}

In situations where new development interacts with an MCA (breaks into or away from MCA development), as part of the PDD process to undertake the mining, all the required checks must be completed and the shaded MCA adjusted on the mine plans. These newly opened MCA excavations are not added to the TCRA for the current year, however, will be included in future years. 


\subsubsection{Maintenance of barricades}

Cross-chained barricades and 'danger mine closure area' signs are installed underground and registered in the signs and barricades log, which is maintained by mine control. The log contains information such as the (laser cut) sign reference number, installation location, date of installation, the reason for installation, who installed it and the department responsible for the sign's maintenance.

Department superintendents are required to undertake a quarterly review of all signs registered to their department to confirm they are still physically in place, correctly registered and still relevant. Aside from routine maintenance, signs are reviewed (removed/installed/moved) during the primary development design process. This process demands checks for type one and two rockfall hazards.

\subsection{Vertical opening pillar hazard assessment control}

An unavoidable hazard created in most underground mining is the potential interaction between people and vertical opening. The nature of sublevel open stoping requires development within the proximity of stopes and vertical openings such as orepasses and vent raises. Management of this risk requires understanding and controlling the pillar of rock that separates people from the vertical opening.

A significant number of these voids are no longer accessible and pre-date modern 3D mine plans and scanning technologies. Due to time-dependent failure, these voids have diameters that potentially increase over time. As the diameter increases, so does the type two risk.

Despite its complexity, the VOPHAC is an evolutionary simplification of the earlier VOMP. All known voids underground are managed through the VOPHAC system. The purpose of the VOPHAC is to assess how pillars between vertically and horizontally oriented development drives are performing and what, if any, controls are required. The VOMP focus was on understanding in detail the nature of all voids near development. However, considering the nature of the type two risk, we realised that it was the pillar of rock that needed to be understood, and only when it existed outside an area closed by the MCA.

The VOPHAC gives guidance as to how to determine if a credible hazard exists, what controls should be considered and provides an assurance framework to ensure the selected controls are effective. For the VOPHAC, all drives that are not barricaded and can physically be accessed are considered active and have the potential to interact with vertical excavations.

All non-entry vertical excavations are treated either as orepasses; having suffered abrasion from rock, or raises; voids that have not been used to transport broken material. Stopes, due to their size, are assessed separately in SVRs. Ladder ways, shafts and other openings that can be monitored from the inside are not included in the VOPHAC but rather under the TCRA.

Every pillar is qualitatively assessed considering dimensions, abrasion, stress, rock quality, orientation to structures, historical performance and orientation. The pillar is then classed either as a 'potential credible hazard' or 'not a credible hazard'. If it has been determined that a credible hazard exist, controls must be put in place to manage the risk. When controls are in place, they must be monitored to ensure they remain effective. The controls, in descending order of effectiveness and the increasing need to be monitored are filling, bypassing, re-enforcing and barricading. Monitoring of the pillars is done through probe holes, instrumentation, laser scans and ground penetrating radar. Only once confirmed as being filled is the risk considered to have been eliminated.

\subsection{Stope void review}

The average stope size for MICO during 2018 is 129,000 t. Historically, stopes were larger, with several stopes as recently as 2015 , exceeding $800,000 \mathrm{t}$. After creating such significant voids with multiple access points into them, we must ensure that the residual hazard is effectively controlled; we consider this a form of stope decommissioning. Not all stopes are completely filled, with some remaining open as mullock dumps or isolated voids; even when filled, there often remains an unfilled void at the crown. Because of the hazard of 
the residual void, at the end of its production every stope undergoes an SVR which ensures accesses are effectively controlled through barriers, and residual voids are understood and overbreak controls are in place.

In many ways, the SVR mimics the VOPHAC in that all the VOPHAC checks are completed. Also, a detailed review is conducted on the design, fill strategy, performance during production and performance post production.

\subsection{Ground awareness training}

Ground awareness training (GAT) at MICO is mandatory for all people working underground. Traditionally, GAT taught basic rock mechanics principles to underground personnel. An example of this is a DVD produced by the Australian Centre for Geomechanics (ACG 2005). MICO no longer gives this type of training to the workforce. The workforce is instead taught how to use the TCRA matrix, and although the matrix is the same as is used by the engineers, the actions are different. Based on the probability rating, they either:

- Continue to work as per normal (green).

- Stop work and request guidance from their supervisor (blue).

- Stop work and request the supervisor get assistance from the rock mechanics that are based underground (yellow).

- Stop work, barricade the area and request the supervisor get assistance from the rock mechanics (red).

Supervisors are given more in-depth training in line with the ACG (2005) DVD as well as spending time with the underground rock mechanics. The time spent with the rock mechanics allows for cross-skilling, with supervisors learning about the science behind the rock behaviour and the engineers learning practical mining methods for addressing the hazards.

One of the most practical methods for dealing with type one rock-related hazards is manual scaling. However, this is no longer as useful in a modern mechanised mine without specialised training and equipment. The drives often exceed $5 \mathrm{~m}$ in height and have surface support. Therefore, personnel cannot safely check-scale the backs of these drives without some form of elevated platform. Once on the platform, the rails and harnesses can severely restrict the range of movement, as well as the ability to escape danger. MICO has two levels of manual scaling training. The basic training is delivered to everyone with the intention they can remove hazards below support grade line or in smaller old drives, and the advanced training is given to those who are required to scale from an elevated platform. Chief among those that require this training are the dedicated scaling crews.

\section{Conclusion}

Rock failure risk management in an underground mine is a complex task in all but the most consistent ground conditions and mine layouts. Variability in the in situ ground conditions, three-dimensional stress changes and blast damage occurring over time, and deteriorating support elements are all factors at play limiting the ability to tactically control all areas of the mine to a defined safety factor. Errors in the management of ground failure hazards have potentially fatal consequences.

Over time MICO has undertaken many process iterations focusing on different aspects of the hazards. Some iterations attempted quantitative assessments of factors such as personnel exposure and pillar failure likelihood. However, these assessments typically were onerous to complete, and the outcome was unconvincing. There were also isolated systems of management for different hazards associated with ground failure, which amounted to a body of work not able to be sustainably completed over time.

Born of necessity, after a run of serious ground failure related incidents, MICO created the MCA process which effectively isolated the workforce from a large portion of the mine. Building on this system, MICO management found great value in simplifying our approach to ground failure hazards, allowing us to make sense of a seemingly insurmountable set of complex interconnected problems. 
The distinction of type one and two hazards, the separation of the mine into accessible and not accessible, and rethinking the various existing ground failure management processes enabled the creation of a holistic and interconnected mine access management system. The system is focused on separating the worker from being exposed to the harmful event, not on understanding and controlling all aspects of ground conditions in the vast and aging Mount Isa Mine.

Simplicity proved to be the greatest asset in the creation of the system. Key recommendations include:

- Only have open what you have to have open.

- Everything that is open is maintained through observation, scaling, support or closure.

- Focus on unwanted event potential, not understanding tactical details about all ground conditions.

- Complete checks to enter/open closed areas.

- Have a QA/QC program that covers all aspects of the system (observation, design, support, closure, barricades).

It is not enough to move mountains; you have to do it safely.

\section{Acknowledgement}

The authors thank the team at MICO who helped us evolve our risk management understanding. Special mentions to Wayne Williams for challenging our thinking, Eileen Rowe for reviewing the paper and the NQ management team for permission to publish this paper. Thank you to Ozlem Yeni for translating our ideas into graphics. Finally, to Aneen Potgieter and Carly Grubb, thank you for supporting our presentation of the paper.

\section{References}

ACG 2005, Reading the Ground: A Geotechnical Hazard Awareness Training DVD for Underground Metalliferous Mine Workers, DVD, ACG, Perth.

ICMM 2015, Health and Safety Critical Control Management Good Practice Guide, ICMM, London.

Jobs, S 2015, Motivating Thoughts of Steve Jobs, Prabhat Prakashan, New Delhi.

Monk, JL 2004, Rockfall Risk Management - Prediction of Rockfall Likelihood at Mount Isa Underground Copper Mine, Bachelor of Engineering thesis, The University of Sydney, Sydney.

Standards Australia 1999, AS/NZS 4360:1999 Risk Management, Standards Australia, Sydney.

Thin, I \& Westerman, M 2001, A Guideline to the Copper Mine Ground Control Risk Management Plan, internal Mount Isa Mines document, Mount Isa Mines, Mount Isa.

WAGCWG 2000, Rock Fall Risk Assessment Guidelines for Underground Mine Access, WAGCWG, Perth. 